\title{
Die brein soos beskou deur die Grieke en Romeine
}

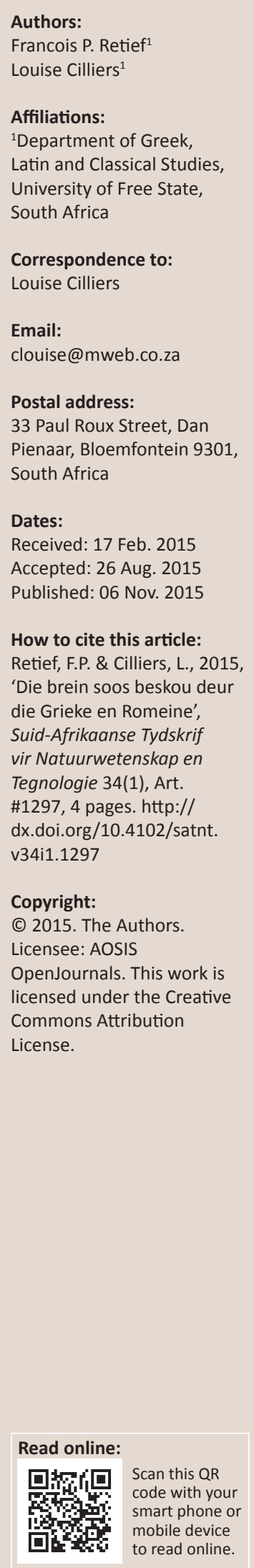

In Ou Egipte is mummifikasie met uitgebreide reseksie of uitsnyding van organe geassosieer, maar geen kennis is geneem van die morfologie van die brein nie. Griekse skrywers van die sesde en vyfde eeue v.C. het die brein aanvanklik gesien as die setel van intelligensie, die orgaan van sensoriese waarneming en gedeeltelik die oorsprong van sperma. Pneuma het 'n belangrike rol in breinfunksie gespeel. Hippokrates was die eerste om die brein te beskryf as 'n dubbele orgaan, wat met harsingvlies (meninges) bedek, funksioneel van pneuma afhanklik en vertolker van begrip is. Tydgenote soos Plato, Aristoteles en Diokles het tot die beskrywing bygedra, maar laasgenoemde twee het beweer dat die hart die middelpunt van intelligensie is en nie die brein nie. Gedurende die laaste helfte van die vierde eeu v.C. is disseksie van die menslike liggaam tydelik aan die mediese skool van Alexandrië toegelaat en het dit tot merkwaardige vooruitgang in die begrip van die menslike anatomie en fisiologie gelei. Herofilus en Erasistratus het uitstekende beskrywings van die struktuur en funksie van die brein gegee wat eers in die tweede eeu n.C. deur Galenus geëwenaar is.

The brain as viewed by the Greeks and Romans. In Ancient Egypt mummification was associated with extensive organ resection, but the brain was removed through a hole cut in the ethnocide bone. It was thus not observed as an organ. Greek writers of the 6 th and 5 th centuries $\mathrm{BC}$ originally said the brain was the seat of intelligence, the organ of sensory perception and partially the origin of sperm. The substance pneuma, originating from fresh air, played an essential role in brain function. Hippocrates initially described the brain as a double organ, covered by meninges and responsible for perception. Contemporaries like Plato, Aristotle and Diocles confirmed the findings though the latter two considered the heart to be the centre of intelligence. During the late 4th century BC, with the onset of the Hellenistic era of medicine, dissection of the human body was temporarily allowed at the medical school of Alexandria, and this led to a remarkable advance in the understanding of human anatomy and physiology under Herophilus and Erasistratus. Their excellent descriptions of the structure and function of the brain was only matched and surpassed by Galen in the 2nd century AD.

\section{Inleiding}

Trepanering van die skedel as terapeutiese maatreël is reeds sedert Neolitiese tye gedoen. Hoewel ' $n$ mate van kennis van die skedelmembrane en veneuse sinusse nodig is om hierdie prosedure suksesvol uit te voer, het dit geen insig in die eienskappe van die brein gebied nie. In hierdie studie word die progressiewe ontwikkeling van kennis met betrekking tot die struktuur en funksie van die brein in die antieke tye kronologies weergegee.

\section{Die vroeë era}

In Ou Egipte was mummifikasie met uitgebreide reseksie van inwendige organe geassosieer, maar die brein is verwyder deur die neus en 'n gat wat in die etmoïedbeen geboor is (Sigerist 1955:353). Die brein is dus nie as 'n orgaan gehanteer nie. Nunn beweer dat die eerste menslike kontak met die brein in ongeveer 1550 v.C. in die Edwin Smith-papirus (gevalle 6 en 8) opgeteken is. Hier vind ons die beskrywing van hoe iemand sy hand deur ' $n$ opening in die skedel gesteek en 'n orgaan met 'n 'geriffelde oppervlak' betas het - die oppervlak het waarskynlik die brein se konvolusies weergegee. Daar is ook kennis geneem van die meningeale bedekking en vog om die brein (Nunn 1999:50-51). Die brein is nie met denke of liggaamsbeheer geassosieer nie. Volgens Sigerist was die enigste funksie van die brein wat opgeteken is die veronderstelde produksie van slym wat tydens verkoue deur die neus te voorskyn kom (1955:353).

Dis moontlik dat die stelling dat menslike sperma gedeeltelik in die brein ontstaan, oorspronklik uit Persië kom. Von Staden noem dat hierdie enkafologene teorie van sperma die Griekse wêreld 
waarskynlik in die sesde eeu v.C. deur Alexander Polyhistor van die skool van Pitagoras bereik het (1989:288-289). Die siening dat 'n substans 'pneuma', 'n belangrike rol in die funksionering van die brein speel, het ook in die sesde eeu ontstaan, aanvanklik deur die geskrifte van Anaximenes (546-528 v.C.). Vir hom het pneuma hoofsaaklik uit buitelug ontstaan. Alkmaeon van Kroton (vroeë 5de eeu v.C.) het beweer dat die brein die setel van die intellek en die orgaan van sensoriese waarneming is (Rocca 2003:60). Die oё, ore, smaak en reuk is almal via openinge in die skedel met die brein verbind. Hy het die teorie van enkefalogene spermproduksie gesteun (Longrigg 1993:53, 56-60). Anaxagoras (500-426 v.C.) het ook geskryf oor sensoriese waarneming en beweer dat die brein spesifieke areas vir hierdie funksie het (Craik 1998:102). Demokritos (460-370 v.C.) het die konsep dat die brein die sentrum van intelligensie is, onderskryf (Longrigg 1993:56).

\section{Die Hippokratiese era}

Hippokrates (469-399 v.C.) word nog steeds as die Vader van die Geneeskunde beskou. Die Hippokratiese Korpus, waaruit ons sal aanhaal, beslaan 69 werke, hoewel nie almal deur Hippokrates self geskryf is nie. Die werke is geskryf oor 'n lang periode in die vyfde en vierde eeue v.C. en in verskillende gebiede (Retief \& Cilliers 2000:10-14). Sy anatomiese beskrywing van die brein was beperk. Volgens hom is die brein 'n dubbele orgaan met ' $n$ dun membraan tussen die twee helftes. Die bloedtoevoer bestaan hoofsaaklik uit twee groot venes, afkomstig van die lewer en milt; veneuse vertakkings bereik ook die regteroor, die regteroog en die neusgate. Die brein is bedek deur twee membrane - 'n veselagtige membraan (dura mater) en 'n vaskulêre membraan (pia mater). Breinfunksie is afhanklik van die bloedtoevoer en die pneuma (lug) wat dit vervoer. Die brein is die vertolker van begrip en gee aanleiding tot vreugde, angstigheid, droefheid, pyn en trane (Hippokrates, The sacred disease :cc. 6, 17, 19).

Verskeie siektes is met die brein geassosieer. Die 'heilige siekte' (epilepsie) was volgens Hippokrates nie heilig nie, maar is veroorsaak deur fisieke abnormaliteite in die brein wat behandel kon word indien dit geïdentifiseer is. Konvulsies was algemeen onder kinders maar het grootliks in latere lewe verdwyn. Dit kon ook deur verskeie ernstige siektes veroorsaak word. Vog op die brein en 'n oormaat van slym veroorsaak kranksinnigheid, ontsteltenis, abnormale visie en gehoor (Hippokcrates, The sacred disease cc.17, 18, 21). Die simptome en oorsake van harsingkoors is uitvoerig beskryf. Nies word veroorsaak deur oorverhitting van die brein, en nekrose van die brein lei tot die dood (Hippokcrates, Epidemics 1.12, 15-22; 2.3, 6, 11).

Die tekstuur van die rugmurg is dieselfde as dié van die brein. Die enkefalogene oorsprong van sperma is aanvaar. Spontane wuif-, gryp- en skeurbewegings van die hande dui op 'n ernstige prognose in harsingskoors. Hewige seisoenale weersomstandighede lei tot breindisfunksie weens die uitermate slegte lug wat ontstaan (Hippokrates: Prognosis c.4; The sacred disease c.20).
Plato (429-349 v.C.) het die brein ook beskou as die sentrum van intelligensie en het geglo dat dit gedeeltelik vir die produksie van semen verantwoordelik was (Longrigg 1993:128, 134). Aristoteles (433-335 v.C.) het diere (maar nie mense nie) gedissekteer en geglo dat die hart, en nie die brein nie, die sentrale orgaan van die mens is. Hy het gereken dat ingebore pneuma wat in die bloed vervoer word vir alle gevoel verantwoordelik is. Aangesien die brein baie minder vaskulêr voorkom as die hart, kon dit volgens hom nie die sentrum van persepsie wees nie. Die brein is ' $n$ dubbele orgaan wat met twee meninges bedek is, en Plato was die eerste persoon wat die serebellum van die serebrum onderskei het. Hy het ook heel eerste sentrale holtes in die brein van diere beskryf. Volgens Plato is dit die funksie van die brein om die liggaam af te koel (Rocca 2003:28-31).

Diokles van Carystus (380-320 v.C.) het slegs vir Hippokrates teruggestaan wat mediese roem betref. Hy het die dier se hart beskou as die sentrum van intelligensie en vir die eerste keer die term 'psigiese pneuma' gebruik om die draer van intelligensie in die bloed te beskryf. Hy het die brein beskryf as 'n dubbele orgaan waarvan die regterkant sensasie en die linkerkant intelligensie beheer (Longrigg 1993:171; Rocca 2003:33). Diogenes van Apollonia (412-324 v.C.) het die brein as die sentrum van intelligensie en sensasie, asook die draer van die siel beskou (Longrigg 1993:60; Rocca 2003:33). Die lug wat deur die bloed gedra word, is die bron van intelligensie (Longrigg 1993:56, 78-79). Theofrastus (372-280 v.C.) het gesê intelligensie is in die lug rondom die brein gesetel. Visie, gehoor, reuk- en smaaksin is via openinge in die skedel na die brein geneem (Hankinson 2008:75).

Lede van die Stoïsynse Beweging (wat in die 4de eeu v.C. gestig is) het geglo dat die siel in die hart gesetel is (Major 1954:141-143; Von Staden 1989:23).

\section{Die Hellenistiese era}

Die mediese skool van Alexandrië wat in die laaste helfte van die vierde eeu v.C. deur die Ptolemeïese konings van Egipte gestig is, het die Hellenistiese era in die geneeskunde ingelui. Vir die eerste keer in die geskiedenis is disseksie (selfs viviseksie) van die menslike liggaam vir 'n kort tydjie toegelaat en dit het tot merkwaardige vooruitgang in die studie van die menslike anatomie en fisiologie gelei - veral die werke van Herofilus en Erasistratus. Daar is selfs beweer dat hierdie werk deur die staat geborg is (Major 1954:141143; Von Staden 1989:155-161; 251-265).

In die ligvan Herofilus (320-260v.C.) se uitstaande anatomiese beskrywings, gebaseer op disseksies van mense en diere (soos die bees), word daar na hom verwys as die 'vader van neuro-anatomie' (Longrigg 1993:211-212; Rocca 2003:38). Hy was die eerste persoon wat al die ventrikels van die brein beskryf het en ook die belangrikheid van elk beklemtoon het. Hy het die vierde ventrikel as die liggaam se fisieke en psigososiale beheersentrum (hegemonikon) beskou en sy koppeling met die rugmurg erken. Sy vaskulêre beskrywing het die samevloeiing van die vier meningeale, veneuse 
sinusse (torcular Herophili) en die rete mirabile (retiform plexus), 'n arteriële kompleks aan die basis van die brein, ingesluit. Laasgenoemde bevinding was egter foutief, aangesien die rete mirabilis in beeste voorkom, maar nie in die mens nie. Sy duidelike beskrywing van senuwees waar hy tussen motoriese en sensoriese senuwees onderskei het, is ' $n$ unieke bydrae: alle senuwees spruit uit die brein of die rugmurg. Hy het minstens sewe paar kraniale senuwees beskryf wat in die brein ontstaan. Dit is egter moontlik dat sommige hiervan meer as een senuwee verteenwoordig. 'Psigiese pneuma' in senuwees aktiveer die motoriese of sensoriese aktiwiteite, en ontstaan in die ventrikels uit natuurlike pneuma in arteries. Sommige ligamente, senings en spiere is beskryf asof hulle vermoëns soortgelyk aan senuwees het. Eudemus, 'n tydgenoot van Herofilus, en Rufus van Efese (1ste eeu n.C.) het Herofilus se sienings aangaande senuwees gestaaf. Herofilus het nie die enkefalogene oorsprong van sperma bevestig nie. Dit wat ons weet aangaande die werk van Herofilus en Erasistratos is beperk tot data wat later deur Galenus opgeteken is (Von Staden 1989:155-161, 251-265).

Erasistratus (315-240 v.C.), 'n tydgenoot van Herofilus in Alexandrië, het ook gebruik gemaak van disseksie van mense en diere. Longrigg beweer dat Erasistratos se beskrywing van die brein selfs beter is as dié van Herofilus. Hy het die meer uitgebreide konvolusies van die menslike brein vergeleke met dié van diere, aan die hoër intelligensie van die mens toegeskryf. Hy het gemeen dat alle senuwees in die intrakraniale gebied ontstaan. Aanvanklik het hy beweer dat senuwees in die meninges ontstaan, maar het later gesê dat omdat senuwees solied en met murg gevul is, dit uit die brein spruit. Erasistratus het baie aandag aan die fisiologie van die brein gegee. Hy het onderskei tussen die 'essensiële pneuma' wat uit die hart en arteries ontstaan, en die 'psigiese pneuma' wat uit die meninges voortspruit. Die 'psigiese pneuma' dring dan die senuwees binne. Soos Herofilus het hy kanale beskryf wat sensasie van die ore, neus, oë en tong na die brein voer (Longrigg 1993:211-212; Rocca 2003:38).

$\mathrm{Na}$ Herofilus en Erasistratos was daar geen beduidende bydraes tot die kennis van die anatomie en funksie van die brein in die Hellenistiese era nie. Met die verbod op disseksie van die menslike liggaam wat na die Herofiliese era in Alexandrië ingestel is, is oorspronklike anatomiese navorsing ernstig gekortwiek en het dit tot die agteruitgang van kennis gelei (Rocca 2003:42).

\section{Die Romeinse era}

Gedurende die eerste en tweede eeue n.C. het 'n aantal anatomiste bydraes gelewer tot die studie van die brein. Marinus van Alexandrië, Quintus, Numisianus, Pelops en Lykus van Masedonië word deur Galenus genoem as belangrike bydraers tot die studie van die brein as die hegemonikon (oorkoepelende orgaan). Die uitsondering was Alexander van Afrodisias, een van die laaste voorstanders van die teorie dat die hart die belangrikste orgaan is. Daar is al aangevoer dat die finale gedeelte van sy De anima doelbewus met Galenus in gedagte opgestel is (Rocca 2003:42, 46, 47).
Dit was egter Marinus van Alexandrië (fl. 120 n.C.) wat met entoesiasme die herlewing van anatomiese navorsing bewerkstellig het. Hy het ' $n$ belangrike bydrae gemaak tot kennis van die anatomie van die brein (bv. 'n studie van die kraniale senuwees, en foramina wat die skedel en die rugwerwels perforeer) en het die konsep van die brein as hegemonikon sterk ondersteun. Hy het 'n teks van twintig volumes oor anatomie geskryf waarin spesifieke navorsing oor die meninges gedoen is, en vrae soos of die brein 'n eie polsbeweging het en of dit vanself asemhaal, is daarin nagevors. Hy het geen disseksies van mense gedoen nie, maar het die bydraes van Herofilus en Erasistratus ten volle onderskryf (Rocca 2003:43-46). Soranus (98-138 n.C.), die beroemde medikus van die 2e eeu n.C., het siriase, 'n hewige koors onder vroue beskryf en dit toegeskryf aan inflammasie van strukture rondom die brein (Temkin 1991:124).

Die statuur van Galenus (129-200 n.C.) as uitstaande medikus van die antieke tye word slegs deur Hippokrates oortref. Hy is in Pergamum gebore, het in Alexandrië in die geneeskunde gekwalifiseer, ' $n$ tyd lank as medikus by 'n skool vir gladiatore in Pergamum deurgebring, maar het die grootste deel van sy lewe in Rome gewoon waar hy o.a. keiser Marcus Aurelius se geneesheer was. Hy het 'n enorme geskrewe bydrae tot die wetenskap gelewer, insluitend minstens 126 boeke oor geneeskunde en 125 oor die filosofie, godsdiens, wiskunde, letterkunde en regsake. Sy persoonlike bydraes tot die anatomie en fisiologie van die brein is gebaseer op disseksie van diere (veral ape en beeste); hy het erkenning gegee aan die werke van vorige skrywers, in die besonder Herofilus en Erasistratus. Dis egter moontlik dat hy in hierdie aanhalings van hulle werk dele vir homself toegeïen het. Sy geskrewe bydraes het dié van enige van sy voorgangers egter ver oorskry (Cilliers \& Retief 2003:81-88).

Die anatomie van die brein is in besonderhede beskryf en stem grootliks ooreen met die beskrywing van die skool van Alexandrië. Bloedtoevoer na die brein het o.a. veneuse bloed in die choroied plexus in die ventrikels, en meningeale, venuese sinusse ingesluit. Arteriële bloed bevat 'essensiële pneuma' en voorsien die retiform plexus aan die onderkant van die brein. Soos egter reeds genoem, kom die retiform plexus (beskryf deur Herofilus) by sommige diere voor, maar nie by die mens nie. Die vier ventrikels van die brein is as uiters belangrik beskou en in groot besonderhede beskryf. Dit is interessant om te let op hierdie belangstelling in die ventrikels, terwyl die funksie van die substansie van die brein as sulks nie in die antieke tye of die Middeleeue beduidend nagevors is nie. Die konsep dat maksimale breinfunksie in die breinsubstansie eerder as die ventrikels voorkom, is vir die eerste keer deur Thomas Willis in die 17 e eeu voorgestel. Galenus het geglo dat die hegemonikon in die ventrikels funksioneer, dat die ventrikels lug van buite deur talle foramina absorbeer, byvoorbeeld, om die kraniale senuwees, en dat 'afvalprodukte' uitgeskei word deur openinge wat egter nie gedemonstreer kon word nie. Die kraniale senuwees word deur die ventrikels geaktiveer. Die 
hipofisêre klier is beskryf. Die rugmurg bestaan uit materiaal soortgelyk aan dié van die brein en is in die omgewing van die vierde ventrikel aan die brein gekoppel. Erkenning is verleen aan die meninges. Alle senuwees bestaan uit murg afkomstig van die brein, en vervoer 'psigiese pneuma' wat vir sensasie en beweging verantwoordelik is.

'Psigiese pneuma' is die belangrikste psigologiese agent van die liggaam, verantwoordelik vir intelligensie en sterk teenwoordig in die ventrikels. Die rasionele siel en 'psigiese pneuma' is beskryf as nou verwante, maar nogtans verskillende entiteite. Die siel is nie in die ventrikels teenwoordig nie, maar in die brein self gesetel. 'Psigiese pneuma' is in die arteriële stelsel uit 'essensiële pneuma' gevorm. Dit vind oorwegend in die retiform plexus plaas, maar in 'n mindere mate ook in die ventrikulêre choroied plexus. Galenus het 'n verskeidenheid siektes (fisiese en psigologiese siektes) beskryf wat deur versteuring van pneumatiese funksie in die ventrikels veroorsaak is (Rocca 2003:51-219, 247).

\section{Slot}

Na Galenus het baie min skrywers in die antieke tye enigsins beduidend bygedra tot kennis van die breinstruktuur of -funksie. Oribasius (320-400 n.C.) het kennis omtrent die ventrikels bevestig, en die belangrikheid van die deurgang tussen die derde en vierde ventrikels beklemtoon (Von Staden 1989:198). Posidonius van Bisantium (laat vierde eeu) het ventrikulêre lokalisasie voorgestel: verbeelding is in die frontale brein, rede in die derde ventrikel en geheue in die agterbrein geplaas. Nemesius van Emesa (fl. 400 n.C.) het die vermoë van verbeelding in die anterior ventrikels, intelligensie in die derde ventrikel en geheue in die vierde ventrikel geplaas (Rocca 2003:246).

\section{Erkenning Mededingende belange}

Die outeurs verklaar dat hulle geen finansiële of persoonlike verhouding(s) het wat hulle op 'n positiewe of negatiewe wyse by die skryf van die artikel kon beïnvloed het nie.

\section{Outeursbydraes}

L.C. (Universiteit van die Vrystaat) het die Griekse en Latynse bronne verskaf en vertaal, en F.P.R. (Universiteit van die Vrystaat) het die mediese aspekte verklaar en in perspektief gestel.

\section{Literatuurverwysings}

Cilliers, L. \& Retief, F.P., 2003, 'Galenus: Prins of pronker?' Akroterion 48, 81-99. http://dx.doi.org/10.7445/48-0-101

Craik, E.M., 1998, Hippocrates. Places in man, Clarendon Press, Oxford.

Hankinson, R.N., 2008, Galen, Cambridge University Press, Cambridge, MA.

Hippocrates et al., 1923, The sacred disease et al., Loeb Classical Library, vol. II, transl. W.H.S. Jones, Harvard University Press, Cambridge, MA

Hippocrates, 1923, Prognosis et al., Loeb Classical Library, vol. II, transl. W.H.S. Jones, Harvard University Press, Cambridge, MA.

Hippocrates, 1923, Epidemics I and III et al., Loeb Classical Library, vol. I., transI. W.H.S Jones, Harvard University Press, Cambridge, MA.

Hippocrates, 1950, 'The seed and the nature of the child', in G.E.R. Lloyd (ed.), Hippocratic writings, transl. I.M. Lonie, Penguin Books, Clays Ltd., St. Ives.

Longrigg, J., 1993, Greek rational medicine, Routledge, London.

Major, R.H., 1954, A history of medicine, Charles Thomas Publications, Springfield, IL.

Nunn, I., 1999, Ancient Egyptian medicine, University of Oklahoma Press, Norman, OK.

Retief, F.P. \& Cilliers, L., 2000, 'Hippokrates: Feit of fiksie', Geneeskunde 10, 10-14.

Rocca, J., 2003, Galen on the brain, Brill, Leiden, Boston.

Sigerist, H.E., 1955, A history of medicine, Oxford University Press, Oxford.

Temkin, O., 1991, Soranus' gynecology, Johns Hopkins University Press, Baltimore, $\mathrm{MD}$

Von Staden, H., 1989, Herophilus. The art of medicine in early Alexandria, Cambridge University Press, Cambridge, MA. 